\title{
Integrated Design Engineering Education within Electrical and Computer Engineering
}

\author{
L. Behjat, S. Magierowski, G. Messier, W. D. Rosehart and H. Zareipour \\ Department of Electrical and Computer Engineering \\ Schulich School of Engineering \\ University of Calgary
}

\begin{abstract}
The paper presents a few simple approaches that have been used to integrate design experiences into regular technical courses. In addition, a possible future initiative to link material from different technical courses through a design experience is outlined. Finally, thoughts on the need to further integrate academic and "work experience" requirements to become a professional engineer are presented.
\end{abstract}

\section{Introduction}

Practicing engineers often face large, open-ended, multidisciplinary projects that tend to require broad technical skills as well as detailed knowledge of a particular area. The success of these projects often requires communication and cooperation between engineers of different disciplines as well as many non-engineering players such as economists, policy makers, scientists and environmentalists. The focus on technical skills found in many Canadian engineering curriculums need to evolve into a deeper design based approach to better prepare our graduates to lead Canada in engineering innovation. In addition, engineering students need to develop strong problem solving skills as well as becoming better critical thinkers.

Often design-based engineering education in Canada is introduced separately from traditional technical and non-technical courses. One common example is the capstone design experience found in most canadian curriculums to meet the following requirement of the Canadian Engineering Accreditation Board (Section 2.2.3, CEAB 2007 Accreditation Criteria and Procedures [1]):

The engineering curriculum must culminate in a significant design experience which is based on the knowledge and skills acquired in earlier course work and which preferably gives students an exposure to the concepts of team work and project management.
Courses focused on design education are an important component of engineering programs, however, it is equally important to develop and deliver courses where design experiences are directly integrated into the gaining of "knowledge and skills" [1] in mathematics, science, and engineering science. Non-technical skills, such as project management, public speaking, and leadership should also be integrated throughout a student's experience, not just in courses associated with the capstone experience and complementary studies.

The aim of this paper is to present a few approaches that have been used to integrate design experiences into regular technical courses. Some thoughts on possible future initiatives are also discussed.

\section{Schulich School of Engineering}

The surge in the oil and gas industries in Western Canada has made Calgary a major engineering centre, with one of the highest density of engineers anywhere in Canada. This has placed the University of Calgary in an ideal position to interact, guide, and learn from these growing industries. To keep up with the demand for high-quality engineering graduates, considerable effort and progress has been made to enhance design engineering education at the University of Calgary.

The Schulich School of Engineering is following a new strategic plan called Beyond Engineering. Undergraduate education is a key component of the plan that states the school aims to graduate "creative thinkers with hands-on experience in solving problems ... we are committed to training imaginative problem-solvers, equipped to tackle what is yet unknown.” [2]

The Department of Electrical and Computer Engineering is home to three CEAB accredited programs, Electrical Engineering, Computer Engineering and Software Engineering. Students enter one of the programs after completing a common year program with all engineering students. Admission to programs is competitive and is based on GPA (grade-point-average) and program 
quota sizes. Courses offered in these programs tend to have a strong laboratory component, with almost all engineering courses having laboratories.

\section{Design Based Experiences}

Curriculums and programs can be developed such that students can gain design and practical design engineering experience through a number of approaches (both inside and outside of the regular class-room environment). Co-op or Internship opportunities tend to provide students with excellent exposure to real-world experiences before completing their program. In addition to the technical development gained through such programs, these experiences can often help students develop a better understanding of the non-technical factors affecting design decisions while enhancing communication and team working skills.

Outside of the classroom, students gain valuable design and decision making skills through participation in engineering teams and organizations, such as Solar Car competitions, Engineers Without Borders (EWB), Formula \& Baja SAE, Great Northern Concrete Toboggan Race, and engineering competitions such as the and the Canadian Engineering Competition.

Engineering programs across Canada have widely adopted capstone design courses, where student (typically in their final year), work on a team project. These projects are design focused and often are linked directly with industrial partners. Unfortunately, capstone design courses tend to be both decoupled from other courses the students are taking and also tend to be departmental specific. There has been some experiences reported in broader multidisciplinary capstone experiences, for example, in [3], experiences gained from offering a capstone project course involving students from Computer, Electrical, Manufacturing, Mechanical, and Software Engineering is presented.

Within a particular class, the use of case studies, open-ended projects, and laboratories that incorporate design experiences can greatly enhance student development. Even though these approaches have been adopted by individuals across Canada, there is a need to further share experiences gained for particular courses and subjects. The Canadian Design Engineering Network (CDEN) has developed and posted several modules over the past decade [4]. However, for the concept of CDENModules to be truly successful, it will require participation from a large number of academics willing to submit their work to the larger community and to also provide updates and evolution of existing modules. Education can never be a static art, it must always be in a state of evolution to be successful.

\section{Design Experiences within Particular Courses}

Over the last several years the authors have worked towards integrating design experiences into regular courses. This has been accomplished using several approaches, of which three simple approaches are discussed in this paper:

1. Industry guest lectures and industry facility tours.

2. Replacement of traditional laboratory exercises with design projects.

3. Replacement of traditional laboratory experiences with design based laboratory experiences.

4. Replacement of traditional assignment and examination questions with design type questions.

In the following sections, samples of each of the above approaches are discussed. Sufficient details are provided for the various samples, so that, if others wish, similar approaches can be utilized elsewhere. In addition, a short discussion outlining the instructors experiences (challenges and rewards) in incorporating design elements is provided.

\subsection{Industry Guest Lectures and Industry Facility Tours}

This section discusses experience gained from exposing forth year students to real-life practice in two power engineering courses. The first course, Power System Analysis (ENEL 587), traditionally covers the modeling, formulation, and analysis of the flow of bulk active and reactive power from generation sites to load centers. This requires spending a significant portion of the lectures on modeling different power system components, such as generators, transmission lines, and transformers. It was found that the students seemed to "lose track of the course" because of the tight course schedule and the volume of the presented materials. In order to give the students an attractive overview of the course that puts together different parts of the puzzle and bridges various presented topics, a senior engineer from the Alberta Electric System Operator (AESO) was invited to the class. By explaining the different roles of the AESO, and presenting some real cases (examples) of systems design, expansion, and analysis, the students were given an opportunity to hear about the real-life application of the course material. The instructor received very positive feedback from the students who indicated that this presentation was a saddle-point in the way they saw the course, and changed their exam-oriented point of view toward the course materials. 
A similar industry guest lecture was held in the course Power Systems Management and Electricity Markets (ENEL 519.48). This course is a combination of power engineering, design, economics, optimization, control systems, engineering system reliability, and investment planning in power systems. Given the broad range of the course coverage, a senior industry manager with both an engineering and economics background presented the real-life applications and value of the course material. This presentation highlighted the importance of team work in engineering design and management, and the fact that engineers need to be equipped with a range of skill sets beyond their own technical discipline.

In addition, to expose students to the physical reality of engineering systems, a tour of a modern power plant was organized for the Power Systems Management and Electricity Markets course. The majority of the course coverage is on managing power generation in presence of economic factors and engineering constraints. It was realized that students sometime have difficulty understanding the physical power generation constraints which led to economic inefficiencies. The reason for this was that electrical engineering students almost always treat power generation as a simple "generation box" without paying enough attention to the details and design of the prime mover. Most physical constraints in power generation, however, result from the mechanics of the prime movers. Thus, a visit to a combined-cycle state-of-the-art gas-fired power generation facility was organized, and students spent half a day with plant engineers, in a relaxed informal manner, discovering various components involved in power generation. According to the students feedback, this was one of their most unique and positive experiences which gave them a clear vision of a real-life engineering system.

\subsection{Design Projects}

In this section, the integration of a design project into a third year computer engineering core course (ENCM 467- Digital Electronics for Computer Engineers) is discussed. The main objective of this section is to illustrate how a traditional laboratory experience can be replaced with design projects. In addition, in designing these experiences, positive motivational techniques [5] such as: demonstrating competency, documenting progress, control over the flow and process, and comparison with valid standards, have been utilized.

The objective of ENCM 467 is to develop a strong understanding of fundamental concepts of digital electronics, with the emphasis on metal-oxide semiconductor (MOS) devices, the basis of contemporary integrated circuits (ICs), and MOS logic design. The course cov- ers a wide range of topics starting from the operation of a single MOS transistor device to designing circuits that can contain thousands of transistors such as (Read Only Memory) ROM units. For the 2006/2007 academic years, the laboratory experiments in this course, were done in a computer lab using the industrial software package Cadence [6]. Cadence is used worldwide in both industry and academia for Integrated Circuits (IC) design, and is available to Canadian universities through CMC Microsystems [7]. The traditional laboratories were replaced with a sequence of design projects. The laboratory time was transformed into consulting time with the course instructor (who was available in the course computer laboratory). The following outlines the different design projects:

1. Part 1: In this part, students design and test different basic logic units and inverters. The students are asked to calculate the outputs of the circuit (voltage and current) and describe how changing characteristics of the circuit (the size and load) will change the output. The students experience design in this laboratory though comparing a set of different designs and seeing where trade-offs are made.

2. Part 2: In this part, the student are asked to design an $A N D$ gate. The students are required to report on the objectives of their design and show how they incorporated speed and the reliance of the circuit into their design.

3. Part 3: In this part, students were given the statement "design an adder circuit" that must meet certain criteria. Students were given 4 weeks to complete the design. The teams competed with each other to win the top design prize for the course (where points are awarded based on the performance of their adder relative to the defined criteria).

In these projects, the students became familiar with the design process, from functionality to optimizing the final product. These laboratory design experiments have been implemented to motivate students in the following ways:

1. Demonstrating competency: The students learn to use a complicated design tool, and by the end of the term they are competent in using this tool.

2. Documenting Progress: The design experiments start from easy and become harder as the term goes by. Therefore, the students can see the progress they have made during the term. 
3. Control over Flow: The students are given a set of design objectives and can choose the flow of their design versus just following a set of instructions. Therefore, they can feel in control.

4. Control over Process: The labs are either fail or pass, and the students are free to work on their design at their own times, therefore, they feel more in control of the process and less anxious about details of marking scheme and the amount of time spent in the laboratory room.

5. Comparison with Valid Standards: The course manual comes with the schematic and layout of a standard design produced by the instructor. In addition, the design competition provides an avenue for the students to compare their design objectives with one-another.

\subsection{Design Based Laboratory Experiences}

One of the simplest ways to transition towards a strong design based curriculum is by adopting design-based laboratory experiences. These laboratory sessions can be viewed as "mini-design projects". In this section, two examples where design based laboratory experiences have replaced traditional laboratories are presented.

\section{Introduction to Basic Circuits using Design}

In most introductory circuit courses (often required by all engineering programs) students are exposed to concepts of equivalent circuits and basic circuit configurations such as current dividers and voltage dividers. A simple example of equivalent circuits is the equivalent resistance of a group of resistors in parallel $^{1}$ and/or series ${ }^{2}$. The principle theory for voltage/current divider circuits is as follows; Voltage Divider: If you place several resistors in series the voltage seen across all the resistors will be divided between each of the resistors in proportion to the magnitude of their resistance; Current Divider: If you place several resistors in parallel, the current through a particular resistor will be inversely proportional to the magnitude of its resistance. The properties of these circuits are based on 3 fundamental laws, Ohm's $\mathrm{Law}^{3}$, and Kirchoff's Current ${ }^{4}$ and Voltage Law $^{5}$ [9].

\footnotetext{
1 "Connected to common points at each end" 8

2 "Coming one after another", "Connected one to another in sequence" 8

${ }^{3}$ The Voltage, $\mathrm{v}$, across a resistor, $\mathrm{R}$, is proportional to the product of the current, $\mathrm{i}$, through the resistor and its resistance $(v=i R)$

${ }^{4}$ The sum of the current into a node (point) in the circuit is equal to the sum of the current leaving that node

${ }^{5}$ The sum of the voltage rises in a "loop" must equal the sum of the voltage drops in that same "loop"
}

Often students complete simple laboratory exercises related to equivalent resistance and current/voltage dividers, where they are instructed to build pre-speficied circuits and then match their observations with theoretical calculations that are likely completed as a pre-laboratory exercise. It is not uncommon that differences between measured and theoretical results are attributed to measurement error and component tolerances without the students really having a strong understanding of these concepts. An alternative, and simple approach, is to have students design circuits to meet certain requirements. Under this approach, students are required to complete pre-laboratory exercises that include providing a summary of the relevant theory, and then design a circuit to meet given functional requirements.

The students were given a limited set of resistors to complete their design. This resulted in students having to consider component tolerances in their designs, typically an under emphasized topic in introductory-level courses. The limited number of components forced the students to design suitable system blocks from their available components. This not only reinforced the application of the 3 laws on a smaller scale but emphasized the need for modular design.

Experience with the above approach has been very positive. Generally, students come to the laboratory period better prepared and have an increased attachment to the work (as it is their design they are implementing, not something copied from a manual). It has been found that with such laboratory approaches students tend not to be rushed to finish the requirements within the laboratory time allowing for significantly more interaction with the course instructor and laboratory assistances. This time is spend discussing their design decisions and debating alternative approaches to solve the problem at hand.

2. ENCM 493 - Software Design for Computer Engineers

ENCM 493 is a course taken by third year computer engineering students. It is their final mandatory course in software development and is meant to teach them the practical skills necessary to work effectively on a software development team. The material includes object oriented software design, software project management, network programming, revision control and unified 
modeling language (UML) basics.

This course is structured such that approximately the first half of the course consists of formal lab exercises and the second half consists of an open-ended design project. The design project is always to write a video game. There are a total of five formal lab exercises that run every week for the first half of the term. These labs are structured to provide the students with the basic tools necessary for writing a game. A summary of the different labs are as follows:

Lab 1: This lab teaches the students how to use a software revision control system and reviews basic $\mathrm{C}++$ fundamentals.

Lab 2: The students practice drawing shapes on the screen using $\mathrm{C}++$ shape objects written with the help of inheritance.

Lab 3: Students practice using function pointers to implement callback routines that animate the shapes and accept keyboard and mouse input.

Lab 4: This lab provides practice implementing network communication using sockets.

Lab 5: The students use threads to implement a socket program capable of simultaneously communicating with multiple clients.

Lab 6: This lab gets the students to animate shapes that move based on commands received over the network from a remote machine.

At the end of the formal lab exercises, students have all the tools necessary to write a game. They are then given their design project assignment which is simply the statement "write a video game". The students are marked primarily on how they apply good software design techniques, not how good their game looks or how fun it is to play.

The level of enthusiasm for this project is always excellent. Besides an obvious interest in the project topic, students appreciate the opportunity to apply what they have learned to solve an ill defined problem. The projects are consistently very well done with many of the best projects showing an extremely sophisticated grasp of good software design.

\subsection{Design Assignments and Examination Ques- tions}

One of the most difficult aspect of delivering a course is choosing appropriate assignments and examination questions. It is not unusual for students to be apprehensive about open-ended design style questions on examinations, however it has been found that this concern can be greatly moderated by properly introducing students to relevant design approaches though examples in classes, tutorials, assignments and laboratories. There is a need for consistency between examinations and other aspects of the course; this does not mean that examinations should simply repeat material. An examination should contain design based questions and new material, presented in a way such that it is a learning exercise in addition to an evaluation exercise.

The authors have generally found that a variety of approaches should be used for assignments. Some questions should be developed for students to complete individually and some should be completed in groups. Sometimes, assignments should be the traditional "take home assignments" and sometimes, they should be completed within a tutorial environment with support from the course teaching team. Design style questions should be included in varying degrees of complexity and difficulty.

\section{Reflections}

\subsection{Integrated Academic and Work Experience}

History with co-operative and internship programs have shown the many advantages of linking academic experiences with "real-world" experiences. Although students gain very valuable design and industrial experience during these short term placements, it is felt that more academic value may be gained. This may be accomplished through linking these experiences with required self-directed courses, or advanced work reports. Although reports are often required during these work placements, often too much emphasis is placed on format with not enough emphasis on technical detail and discovery.

In many ways, there is a separation between the university "course" experience and the "work experience" required to become a registered engineer. For example, once a future engineer completes his/her baccalaureate, there is a requirement for up to 4 years of work experience before registration requirements as an engineer are met. Just as "real-world" experiences greatly enhance a Bachelor's degree (Co-op, Internship), there are reasonable arguments that post-degree courses can significantly enhance work experience requirements. Most provincial engineering associations require that regis- 
tered engineers complete some type of annual professional development. A possible extension to this would be for EngineersCanada or the various provincial engineering associations to offer a certificate program that future applicants must complete before registration. A candidate should not be allowed to register to start the certificate until an engineering baccalaureate or equivalent is completed. The courses in the certificate could be a combination of technical and nontechnical courses. Some of the courses could be offered by universities/academics, where others could (and should) be offered by senior experienced engineers (in a similar way, senior engineers should offer more guest lectures and even courses inside universities).

\subsection{Design Experiences linking Multiple Courses}

Currently, the Department of Electrical and Computer Engineering is engaged in an initiative to not only integrate a design experience into traditional lab exercises but also to reinforce the connection between courses in the second year of the electrical engineering program.

In second year, students take ENEL 327 - Signals and Systems and ENEL 343 - Circuits II. ENEL 327 focuses primarily on time and frequency domain signal analysis while ENEL 343 teaches the design of frequency selective circuits. Currently, students are assigned lab exercises in both courses. These exercises are primarily designed to reinforce lecture material where students work through several steps in each lab to arrive at a single answer.

An initiative is currently underway to remove the lab exercises and their associated time slots from ENEL 327 and 343. That time will then be used to form a new second year design course that integrates the existing ENEL 327 and ENEL 343 exercises into a design experience. Combining the lab exercises from the two courses will also reinforce the very complementary nature of the ENEL 327 and ENEL 343 material.

The proposed course will be structured such that students are presented with an open-ended design problem at the start of the term. As the course progresses, the students will go through some traditional lab exercises that reinforce the ENEL 327 and ENEL 343 material while, at the same time, gradually giving them the tools they need to address the design problem.

This is best illustrated by using an example. At the start of the term, students could be presented with a music signal distorted by a $60 \mathrm{~Hz}$ hum. They will then go through a series of lab exercises related to ENEL 327 that will show them how to view the signal in the frequency domain such that the $60 \mathrm{~Hz}$ tone becomes apparent. Students will then go through some exercises related to ENEL 343 that will teach simple filter design.
After that, they will apply what they have learned to develop filters that can remove the $60 \mathrm{~Hz}$ distortion.

The open-ended nature of this project is such that the students are never told what the signal distortion is, exactly what filter design they need or exactly how that design should be optimized. It is likely that students will adopt several different designs with the final test being how much sound quality is improved.

\section{Summary}

The paper presents some experiences in incorporating design approaches within technical courses across electrical and computer engineering. Some thoughts on integration between academics and "work experiences" is discussed. Finally, an initiative to link 2 courses in second year through a design course is presented.

\section{References}

[1] G. R. Peters, Accreditation Criteria and Procedures. Canadian Engineering Accreditation Board, Canadian Council of Professional Engineers, 2007.

[2] "BEYOND ENGINEERING, Schulich School of Engineering 2008-2013 Strategic Plan,” Website accessed May 2008, http://www.schulich.ucalgary.ca/.

[3] P. Jazayeri, W. Rosehart, and D. Westwick, "Experiences and proposals for interdisciplinary engineering design courses," in Proc. of the Second CDEN International Conference on Design Education, Innovation, and Practice, Kananaskis, Alberta, Canada, July 2005.

[4] “CDEN/RCCI Design Modules," Website accessed May 2008, http://www.cden.ca/modules.htm.

[5] M. Svinicki, Learning and Motivation in the Postsecondary Classroom. Bolton, MA, USA: Anker Pulishing Company, Inc., 2004.

[6] "Cadence Design Systems, http://www.cadence.com/," Website accessed May 2008, http://www.cadence.com/.

[7] "CMC Microsystems, http://www.cmc.ca/index.htm," Website accessed May 2008, http://www.cmc.ca/index.htm.

[8] The New Oxford American Dictionary, Second Edition. Oxford University Press, 2005.

[9] J. W. Nilsson and S. A. Riedel, Electric Circuits (7th Edition). Prentice-Hall, 2005. 